\title{
Properties of Core-half Wrapped Shell Structure Wood- polymer Composites Containing Glass Fiber-reinforced Shells
}

\author{
Runzhou Huang, ${ }^{\mathrm{a}, *}$ Xian Zhang, ${ }^{\mathrm{a}}$ Zhuangzhuang Teng, ${ }^{\mathrm{a}}$ and Fei Yao ${ }^{\mathrm{b}}$ \\ Glass fiber (GF) is commonly applied as a filler in the preparation of \\ polymer composites. Due to the presence of GF, composite mechanical \\ performance, flame resistance, and thermal performance could be greatly \\ improved. The influence of a GF-filled polymer shell layer was investigated \\ relative to the morphology, mechanical, thermal, and fire flammability \\ performance of the core-half wrapped shell structured wood high-density \\ polyethylene (HDPE) composites prepared via co-extrusion. The use of \\ the relatively less-stiff pure HDPE with high linear coefficients of thermal \\ expansion (LCTEs) lowered the general thermal stability and modulus of \\ the wood polymer composites (WPCs). Flexural and thermal expansion \\ properties were improved for the GF-filled HDPE shells in comparison to \\ the unmodified material, enabling a well-balanced performance of this \\ novel core-shell material. Implementation of GF-modified HDPE or \\ unmodified HDPE layers as a shell for WPC core remarkably improved the \\ impact resistance of the co-extruded WPCs. In comparison with \\ composites possessing unmodified HDPE shell, the flame resistance \\ performance of the shell layer was slightly improved in case that the GF \\ content was below $25 \mathrm{wt} \%$. A slight decrease in composite general heat \\ release and rate was discovered in case that the GF content was greater \\ than $25 \mathrm{wt} \%$.
}

Keywords: Core-half wrapped shell structure; Wood polymer composites; Thermal expansion; Mechanical; Flammable properties

Contact information: a: College of Materials Science and Engineering, Nanjing Forestry University, Nanjing, 210037, China; $b$ : School of Renewable Natural Resources, Louisiana State University Agriculture Center, Baton Rouge, Louisiana 70803, USA; *Corresponding author:

runzhouhuang@njfu.edu.cn

\section{INTRODUCTION}

The commonly used polymers and biomass fibers (such as woods and bamboos) are renewable and degradable materials. In China, approximately 0.564 billion tons of household wastes are produced annually, including tremendous amounts of renewable resources such as plastic and biomass fiber (Ansari and Navalurkar 1993; Yao and Wu 2010; Kim et al. 2013). The rational utilization of composite materials with fiberreinforced polymers not only can replace woods to address the issue of insufficient supply of raw materials for wood-based panels, but waste plastics also can be recycled, leading to the saving of resources. With the extensive application of wood polymer composite (WPC), the novel core-shell structure WPC has been developed in an attempt to overcome the above-mentioned problems. Different from WPC with traditional homogenous structures, the core-shell WPC is usually prepared through a co-extrusion processing method, which constructs a multi-layer structure through extruding and fusing two or more polymers into one single mold (Yao et al. 2008). Different characteristics of prepared multi-layer 
composite materials was found to greatly alter the performance of composites compared with the core layer, and the co-extrusion technology has become a promising processing technique for the fabrication of polymer matrix composite materials. For instance, some composite features, such as good resistance to oxygen and moisture, shading and heat insulation, bonding strength, and good mechanical performance properties, may be realized through reinforcing the shell layer of composites. Moreover, the co-extrusion process significantly reduces the material and production costs, which can recycle the used materials and thereby improve the raw material utilization rate (William 1998; Son et al. 2003).

The extensive application of the core-shell WPC can greatly improve the material utilization rate and enhance the performance of composite materials (Nielson and Landel 1993; Klyosov 2007). The shell layer is constituted by pure polymers or thermoplastic resin matrix composites, and the core layer is made up of traditional WPC. In this core-shell structure, the property of the shell layer is the major factor to influence the overall performance of the structure WPC (Liu et al. 2010). For instance, compared with WPC with a homogenous structure, WPC using pure high-density polyethylene (HDPE) and polypropylene (PP) as the shell layer has a low thickness swelling rate of water absorption. However, core-shell WPC applies thermoplastic resin with a low modulus and high linear coefficient of thermal expansion (LCTE) as the shell layer, which generates detrimental effects on the thermal stability and modulus of the core layer. Therefore, the shell layer property is modified by the reinforced materials to enhance the overall performance of core-shell WPC.

Many efforts have been devoted to improving the thermal and mechanical properties of the core-shell structure WPC via co-extrusion technology. For instance, Jin and Matuana (2010) investigated the core-shell WPC using the $\mathrm{HDPE}-\mathrm{TiO}_{2}$ composite as the shell layer. Kim et al. (2013) utilized carbon nanotubes and precipitated calcium carbonate (PCC) as the reinforced materials to alter the shell layer performance. Yao et al. (2010) investigated the manufacturing process of WPC and analyzed the impact of surface features on the strength and bending behavior of composites.

For the Crystal White series products from Louisiana-Pacific and the Celucor series products from Royal Group Technologies, polyvinyl chloride (PVC) was adopted as the matrix to produce the co-extrusion-type WPC. The resulting material exhibits excellent strength and durability compared with traditional PVC of WPC. For the CXline series products from Gaf Decking Systems LLC, the PP shell layer and WPC core layer composite structure were utilized, rendering 25 years of quality guarantee. Compared with traditional WPC with 10 years of quality guarantee, the co-extrusion product exhibits obvious high weather fastness. The multi-extrusion core-shell WPC jointly developed by Badische Anilin-und-Soda-Fabrik (BASF) and Washington State University contains the HDPE shell layer and WPC core layer, substantially improving the aging resistance. Huang et al. (2012b) investigated the impact of different wood fibers and coupling agent contents on the mechanical and thermal expansion performance of traditional structural woodplastic composites. Meanwhile, in that report, efforts were made to continue to observe WPC's preparation process, mechanical, and thermal performance of WPC; the thermal expansion properties of composites were intensively studied; the finite element model of the thermal expansion properties of WPC was also constructed (Huang et al. 2012a) .

In the present work, the influence of the addition amount of the shell layer filling on the morphology, mechanical, thermal, and fire flammability performance of the coextrusion WPC with core-half wrapped shell is analyzed. Specifically, the objective of the 
research was to discover: (1) the effects of different addition amounts of shell layer filling on the composite properties; and (2) the effects of interfacial properties between the shell layer and core layer on the flame retardation of the co-extrusion WPC.

\section{EXPERIMENTAL}

\section{Raw Materials}

The GF-filled HDPE pellets containing $50 \mathrm{wt} \%$ of GF (treated with silane prior to compounding) were provided by Tianjiang Inc. (Nanjing, China). Polar wood flour (WF 20-mesh size) was acquired from Dare Wood Fibers Inc. (Zhenjiang, China). High-density polyethylene (HDPE) of AD60 grade with $0.75 \mathrm{~g} / 10$ min melt-flow index (MFI) at $185{ }^{\circ} \mathrm{C}$, $2.08 \mathrm{~kg}$ and density of approximately $0.96 \mathrm{~g} / \mathrm{cm}^{3}$ was provided by Julong Chemical Co. (Nanjing, China). Maleic anhydride grafted polyethylene (MAPE, EpoleneTM G2608 grade) with MFI = approximately 6 to $10 \mathrm{~g} / 10 \mathrm{~min}\left(190{ }^{\circ} \mathrm{C}\right.$ and $2.16 \mathrm{~kg}$ applied weight $)$, molecular weight of $65 \mathrm{~kg} / \mathrm{mol}$ and an acid number of $8 \mathrm{mg}$ of $\mathrm{KOH}$ per g of MAPE was supplied by from Eastman Chemical Co. (Houston,TX, USA). Lubricant (TPW 306 grade) was bought from Struktol Co. (Houston, TX, USA).

\section{Composite Formulation}

A few sample groups for co-extruded WPCs had been set up prior to the research work. The composite core was made up of HDPE, WF, lubricant, MAPE, with a weight ratio of 37:55:5:3. While the shell constituted six blends, which covered a GF and five loading rates $(0,5,10,15,25,35$, and $50 \mathrm{wt} \%$ of total composite weight for filler reinforced HDPE) for the shell. The control group included pure HDPE and core-containing original composites.

\section{Composite Manufacturing}

Co-extrusion test was carried out using two feeders for plastic pellets and wood fiber/lubricant/talc mixtures via the co-extrusion system, as shown in Fig. 1 (Yao and Wu 2010).

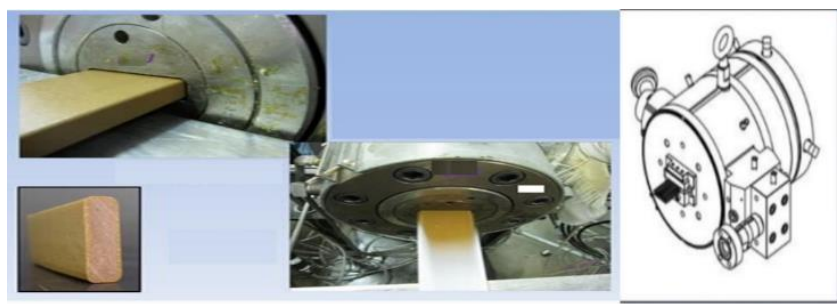

\section{Co-extrusion die}

Fig. 1. Co-extrusion system

The extrusion system comprised one 32-mm conical Brabender (Brabender Instruments Inc., South Hackensack, NJ, USA) and the Leistritz Micro-27 twin-screw extruders (Leistritz Corporation, Allendale, NJ, USA) matched with the shell and for the core. The profile with a target cross-section size of $13 \mathrm{~mm} \times 50 \mathrm{~mm}$ maintained by the vacuum sizer was obtained from a customized die. The co-extruded profiles, hauled by a downstream puller, would flow via a water bath about two meters long under constant water spray. In case of extrusion, the temperature of the die was set to be 160 (at the feeder side), and then $165,165,170,175,165,155,145,135$, and $155^{\circ} \mathrm{C}$ (at the die side) for the 
core. Due to the difference in formulation, the temperature of extrusion in the shell varied in the range of 145 to $165^{\circ} \mathrm{C}$.

\section{Methods}

Morphology

Analysis on cross-sectional morphology was accomplished using by field-emission scanning electron microscopy (FE-SEM) using with Quanta TM 3D FEG Dual Beam instrument (Hitachi Ltd., Tokyo, Japan). To prepare the SEM samples, a sample was soaked in liquid nitrogen until it became brittle. The sample piece was then broken in half to expose the cross-section, which was then covered with gold (ION Sputter Coater 150; Bruker, Shanghai, China) to minimize sample charging. Au was applied on the fractured cross-sections were coated with Au to minimize sample charging.

\section{Static properties}

Flexural testing (four-point) was conducted. Samples $390 \mathrm{~mm}$ long, $50.4 \mathrm{~mm}$ wide, and $12.5 \mathrm{~mm}$ thick were subjected to four-point bending flexural tests performed by an Instron 5582 (Instron, Norwood, MA, USA) instrument in accordance with the ASTM D6272 (2002) standard using $8.7 \mathrm{~mm} / \mathrm{min}$ crosshead speed and $250 \mathrm{~mm}$ span length. Impact strength analysis was conducted on $63.5 \times 12.7 \times 3 \mathrm{~mm}^{3}$ samples using the Tinius Olsen Mode 1892 (Tinius Olsen, Horsham, PA, USA) tester on $63.5 \times 12.7 \times 3 \mathrm{~mm}^{3}$ samples.

\section{Thermal expansion measurements}

Sampling cut was made with one mini-table saw along the longest side of the 43.5 $\times 12.7 \times 5.4 \mathrm{~mm}^{3}$ part. Measurement of the linear coefficients of thermal expansion (LCTEs) was made along the sample length in the range from 25 to $-13{ }^{\circ} \mathrm{C}$ and from -13 to $60{ }^{\circ} \mathrm{C}$. The Mitutoyo (Mitutoyo, Osaka, Japan) digimatic indicator with $\pm 0.01 \mathrm{~mm}$ was chosen from the thermal expansion experiment. Before the test, samples were treated at 60 ${ }^{\circ} \mathrm{C}$ and $-13{ }^{\circ} \mathrm{C}$, respectively. Each group contained five samples. The calculation of LCTE was made through measuring the change of sample size in pre-conditioning and postconditioning stage. The algorithm for the calculation of LCTE $\left(\alpha_{\mathrm{L}}, 1 /{ }^{\circ} \mathrm{C}\right)$ followed the expression as below,

$$
\alpha_{L}=\frac{1}{L} \frac{d L}{d T}
$$

where $L$ means sample length $(\mathrm{mm})$, and $\mathrm{d} L / \mathrm{d} T$ means the length change rate per degree.

\section{Flammability test}

A Standon Redcroft cone calorimeter purchased from Fire Testing Technology Ltd. (London, England) was utilized in the flammability test on samples. The test rigorously abode by the ISO 5660-1 (2002) procedure. The samples were positioned in the $\mathrm{Al}_{2} \mathrm{O}_{3}$ crucible (100 mm long and $100 \mathrm{~mm}$ wide) lined with Al foil. The assembly with horizontal installation on the calorimeter loader was then heated at $50 \mathrm{~kW} / \mathrm{m}^{2}$. The temperature on the upper surface (covered shell layer) of samples in the test approached $780{ }^{\circ} \mathrm{C}$. The flame was directed towards the surface that is covered by the glass-containing shell. Every sample group should be measured repeatedly for three times. Results showed the reproducibility was within $\pm 7 \%$. 


\section{Statistical data analysis}

Statistical analysis software SPSS 20.0 was adopted in the pair-wise comparative analysis on measured performance in Duncan's multiple range tests (IBM Corp., Armonk, NY, USA), thus presenting the statistical sequence of all properties at the $5 \%$ significance level.

\section{RESULTS AND DISCUSSION}

\section{Structure}

Figure 2 shows the photographs of structured WPCs with core-half wrapped shell structure and containing GF-reinforced shells. The shell thickness averaged at $1.0 \mathrm{~mm}$ with the $10-\mathrm{mm}$-thick core materials.

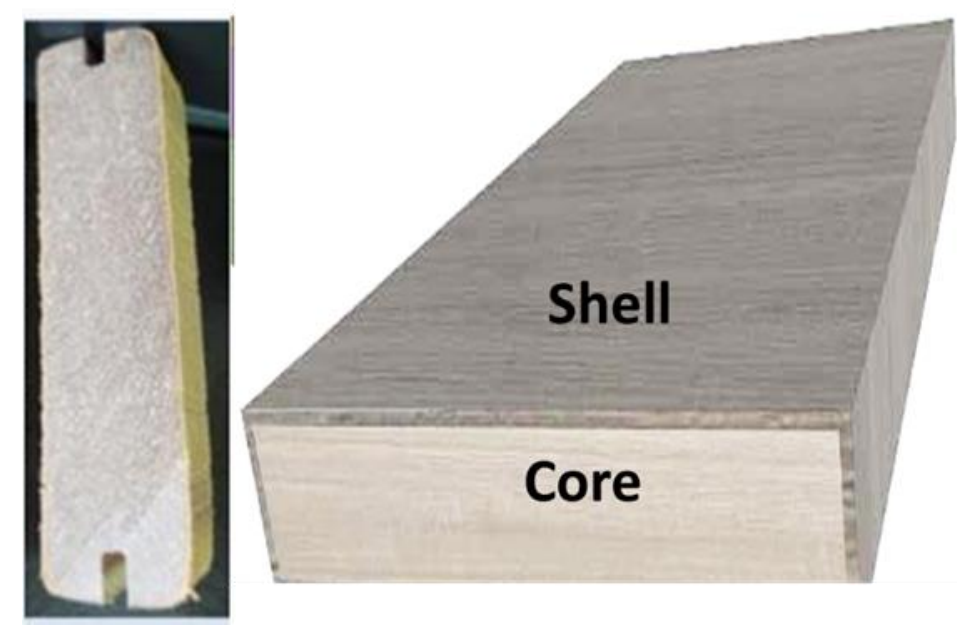

Fig. 2. Extruded co-extruded core-half wrapped shell-WPCs

\section{Morphology}

The core/shell interface in the co-extrusion WPC is shown in Fig. 3. It can be seen that there were many fractured glass fibers (GFs) on the shell layer (Fig. 3a), which are vertical to the fracture surface (along the direction of injection molding materials). When GFs break, some GFs were pulled out, while most of them were retained within the plastic matrix. This phenomenon suggested the favorable binding of the HDPE matrix with GFs in the HDPE/GF composite. This was because GFs were treated with silicon solution before granulation, which served as the coupling agent. As a result, the HDPE matrix combined well with GF filling in the HDPE/GF composite due to the coupling agent. Meanwhile, the figure shows that the core layer and shell layer exhibited a good interfacial bonding, thus optimizing the modification effect of the shell layer material.

The SEM image of the shell layer material in the co-extrusion WPC is shown in Fig. 3b. As shown, GFs were subject to obvious fracture, most of which remained within the plastic matrix instead of removal. Because GF played a role of weight bearing, a higher GF content indicated a stronger capacity to bear external force. Meanwhile, the matrix mainly undertook a role of fiber adhesion and stress transmission. When an external force was applied on the composite, the stress was transmitted uniformly onto fibers through the matrix, suggesting favorable integration between GF and the HDPE matrix. The reason is 
the same as that explained in Fig. 1. Specifically, the silicon solution for GF treatment performs as a coupling agent, which can reinforce the interfacial compatibility of HDPE/GF composite. The GF is sufficiently impregnated and bonded to the HDPE matrix, and the composite exhibits good interfacial properties. The high strength of the GF filling sufficiently exerts its reinforcing effect.

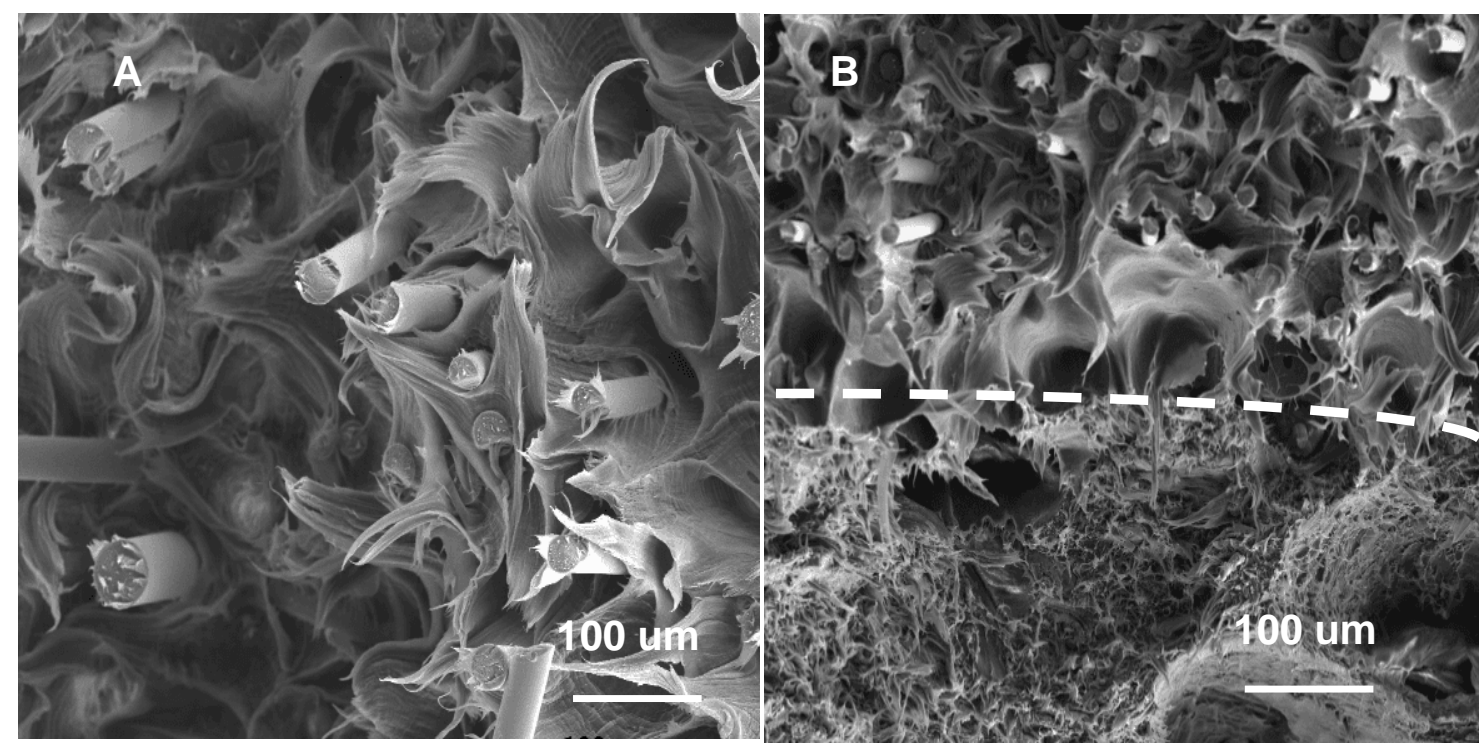

Fig. 3. SEM micrographs of co-extruded WPC containing GF-filled shell: (A) Shell layer, (B) corehalf wrapped shell interface

The SEM image of the core layer material in the co-extrusion WPC is displayed in Fig. 3. Some fibers were removed in the core layer, leading to the formation of voids. This suggested that wood fibers were clearly visible in all directions of the composite fracture section. In Fig. 3B, the dashed curve line indicates that wood fibers were removed when the fracture occurred. As a result of the high concentration of wood fibers in the core layer composite $(55 \mathrm{wt} \%)$, the wood fibers were poorly dispersed in the matrix, and they were inclined to aggregation. When an external force was applied in the composite material, stress concentration was formed around the wood fibers, leading to the detachment of wood fibers from the matrix at the composite interface.

\section{Mechanical Properties}

Table 1 presents the flexural performance of the GF/HDPE composites containing varying GF contents. A remarkable increase can be seen in below and above $50 \% \mathrm{GF}$ content. Flexural strength and modulus of GF-reinforced shell layer concurrently grew with the rise of GF loading level. Core composites demonstrated flexural modulus equal to 3.35 $\pm 0.31 \mathrm{GPa}$. The GF filling improved composite moduli relative to composites with unloaded shell, suggesting a positive impact generated by WPC on composite stiffness.

GF loading produced remarkable effects on the flexural strength of the composites as its content was raised from $0 \%$ to $50 \%$. The flexural strength of co-extruded WPC with pure HDPE shell (equal to $22.38 \pm 2.3 \mathrm{MPa}$ ) increased to $43.81 \pm 4.1 \mathrm{MPa}$ at $50 \% \mathrm{GF}$ loading, which was 1.35 times higher than flexural strength of core without shell layer.

Filler alignment is an important constituent that contributes to the flexural strength of resulting composites. Flexural strength values of WPCs synchronized with flexural 
modulus values in the variation trend, most likely because GF addition provided the composites with both strength and stiffness. The GF content in the shell did not leave any significant influence on the flexural strength of the structured material containing less than $25 \mathrm{wt} \%$ of the GF loading level. This was possibly because the core was strong, resulting in more strength in the core layer. Therefore, the prime influence factor of bending strength was actually the core/shell interface comprising identical HDPE and different GF contents regardless of the GF filling (Ansari and Navalurkar 1993; Bengtsson and Oksman 2006; Jin and Matuana 2010).

The impact strength values of the core-half wrapped shell structure and corewithout shell composites are shown in Table 1.

Table 1. Summary of Mechanical and Thermal Expansion Properties of Core and Core-Half Wrapped Shell WPCs

\begin{tabular}{|c|c|c|c|c|c|c|}
\hline \multirow[t]{2}{*}{ System } & \multirow{2}{*}{$\begin{array}{c}\text { GF } \\
\text { Content } \\
\text { in Shell } \\
\text { Layer } \\
(w t \%)^{a}\end{array}$} & \multirow{2}{*}{$\begin{array}{l}\text { Impact } \\
\text { Strength } \\
\left(\mathrm{KJ} / \mathrm{m}^{2}\right)\end{array}$} & \multirow{2}{*}{$\begin{array}{c}\text { Flexural } \\
\text { Modulus } \\
\text { (GPa) }\end{array}$} & \multirow{2}{*}{$\begin{array}{c}\text { Flexural } \\
\text { Strength } \\
\text { (MPa) }\end{array}$} & \multicolumn{2}{|c|}{ LTCE $\left({ }^{-6} /{ }^{\circ} \mathrm{C}\right)$} \\
\hline & & & & & $\begin{array}{c}-13 \text { to } 60 \\
{ }^{\circ} \mathrm{C}\end{array}$ & -13 to $25^{\circ} \mathrm{C}$ \\
\hline \multirow[t]{3}{*}{ Core } & 0 & $3.8(0.35) \mathrm{A}$ & $3.35(.031) \mathrm{E}$ & $32.32(0.31) \mathrm{C}$ & $43.1(4.2) \mathrm{A}$ & $39.6(3.5) \mathrm{A}$ \\
\hline & 0 & $6.58(0.61) \mathrm{C}$ & $2.01(0.18) A$ & 22.38 (2.3)A & $79.7(7.0) \mathrm{G}$ & $76.3(6.8) \mathrm{G}$ \\
\hline & 5 & $6.11(0.57) \mathrm{B}$ & $2.36(0.22) A$ & $26.33(3.1) \mathrm{A}$ & 73.9 (6.9)F & $71.1(5.9) \mathrm{F}$ \\
\hline \multirow{5}{*}{$\begin{array}{c}\text { Core-half } \\
\text { Wrapped } \\
\text { Shell }\end{array}$} & 10 & $5.81(0.51) \mathrm{B}$ & $2.77(0.21) \mathrm{B}$ & 30.06 (3.3)B & $68.7(5.7) \mathrm{E}$ & $66.1(5.2) \mathrm{E}$ \\
\hline & 15 & $6.31(0.48) \mathrm{C}$ & $2.99(0.29) \mathrm{C}$ & $33.45(3.2) \mathrm{C}$ & $65.6(5.9) \mathrm{E}$ & $60.3(5.1) \mathrm{D}$ \\
\hline & 25 & $6.91(0.68) \mathrm{D}$ & $3.08(0.32) \mathrm{D}$ & $37.33(3.8) \mathrm{D}$ & $59.3(6.1) \mathrm{D}$ & $57.1(5.8) \mathrm{D}$ \\
\hline & 35 & $7.53(0.61) \mathrm{E}$ & $3.37(0.23) \mathrm{E}$ & 40.11 (3.3)E & $53.3(4.9) \mathrm{C}$ & $50.1(4.8) \mathrm{C}$ \\
\hline & 50 & $8.17(0.77) \mathrm{F}$ & $4.03(0.32) \mathrm{F}$ & $43.81(4.1) \mathrm{E}$ & $48.3(4.1) \mathrm{B}$ & $45.6(3.8) \mathrm{B}$ \\
\hline
\end{tabular}

a The content of overall fillers was registered as GF on account of the total composite weight; there is no significant difference in the mean of same capital letter of all properties at the $5 \%$ significance level; statistics in the bracket indicated the standard deviation of the five samples in each group.

The impact strength of the core-only composites was $3.8 \pm 0.35 \mathrm{~kJ} / \mathrm{m}^{2}$. The impact strength value of the virgin HDPE shell-containing composites grew to $6.58 \pm 0.61 \mathrm{~kJ} / \mathrm{m}^{2}$. Core-half wrapped shell-structured WPCs experienced a sharp rise in impact toughness in comparison with the core-without shell materials. The impact toughness of the co-extruded composites were reduced when they were covered with a shell. The impact toughness of the structured materials was reduced as the GF content was raised, indicating a somewhat linear correlation. As a consequence, the toughness of composites may be enhanced by the shell layer with a higher loading level. The same trend was also seen in the formerly reported co-extruded Barite-filled shell WPCs (Yao and Wu 2010). As a result, the shell layer can protect the brittle core. The presence of the stronger HDPE content containing in the shell endowed the core-shell-structured WPCs with higher flexibility and stiffness. Given that more energy was absorbed by shell, the shell layer prohibited crack propagation during fracture. For the GF loading ranging from $5 \mathrm{wt} \%$ to $25 \mathrm{wt} \%$, low GF content resulted in the poor stiffness of the shells because of the weaker impact strength of the composite. GF loading level equal to $50 \mathrm{wt} \%$ was conducive to the improvement of composite toughness especially in comparison with filled-shell WPCs. 


\section{Thermal Expansion Performance}

Table 1 summarizes the LCTE values for the core-half wrapped shells structured WPCs containing neat HDPE cap and GF fillers in the shells in a cooling cycle (25 to -13 $\left.{ }^{\circ} \mathrm{C}\right)$ and heating cycle $\left(-13\right.$ to $\left.60^{\circ} \mathrm{C}\right)$. In a core-half wrapped shell-structured WPCs system, using a virgin HDPE shell with a high LCTE of overall composites, the LCTEs of the structured WPCs were reduced with the increase of GF content in the shell layer.

For the non-co-extruded composites (core-without shell layer), the LCTEs were the minimum in comparison with the counterparts in the co-extruded composite system, which were $(39.6 \pm 3.5) \times 10-6 /{ }^{\circ} \mathrm{C}$ and $(43.1 \pm 4.2) \times 10-6 /{ }^{\circ} \mathrm{C}$ for the 25 to $-13{ }^{\circ} \mathrm{C}$ and -13 to 60 ${ }^{\circ} \mathrm{C}$ ranges, respectively, with a neat HDPE shell and under heating and cooling cycles. With the pure HDPE-coated core, the LCTEs grew to $(79.7 \pm 7.0) \times 10-6 /{ }^{\circ} \mathrm{C}$ and $(76.3 \pm 6.8) \times$ $10-6 /{ }^{\circ} \mathrm{C}$ for the co-extruded WPCs with half wrapped shell. Thus, applying a material with high-LCTE coating to HDPE shell, which was deposited on the stiff core with thermal stability, enhanced LCTE of the overall composite. The LCTE values decreased to ( $48.3 \pm$ $4.1) \times 10^{-6} /{ }^{\circ} \mathrm{C}$ and $(45.6 \pm 3.8) \times 10^{-6} /{ }^{\circ} \mathrm{C}$ for structured WPCs with $50 \mathrm{wt} \% \mathrm{GF}$ in the shell with cooling and heating cycles, respectively. Such values were in proximity to corresponding core-only LCTE values. As a result, the LCTE value of the composites could be efficiently lowered through introducing GFs with favorable thermal stability performance to the shell layer. The reason may be related to the GF-filled HDPE composites for shell layer and consequent lower LCTE for the shell layer related to the entire composite. Regardless of any change in the content of GF, the shell filler remained to be the main influence factor of thermal expansion. Detrimental impacts generated by the shell to LCTE composites could be mitigated through applying thinner shells and GFcontaining shell materials with stronger thermal stability and modified surface (Kim et al. 2012; Huang et al. 2013).

\section{Flame Resistance}

Test parameters, comprising peak heat release rate (PHRR), total heat released (THR), average heat release rate (AHRR), average mass loss rate (AMLR), average effective heat of combustion (AEHC), and average specific extinction area (ASEA), were derived by the cone calorimetry test as shown in Table 2. Figures 4 and 5 show the composites required by the test in this research.

The flame retardation of the co-extrusion WPC is displayed in Table 2. Indexes that reflect the flame retardation, including HRR, AHRR, THR, average specific mass loss rate, ASEA, and average effective heat combustion (EHC) value, change with the addition of the shell layer GF. 
Table 2. Cone Calorimetry Data for Co-extruded WPCs with Half Wrapped Shell

\begin{tabular}{|c|c|c|c|c|c|c|c|}
\hline System & $\begin{array}{c}\text { GF Content } \\
\text { in Shell } \\
(\mathrm{wt} \%)\end{array}$ & $\begin{array}{c}\text { PHRR } \\
\left(\mathrm{kw} / \mathrm{m}^{2}\right)\end{array}$ & $\begin{array}{c}\text { AHRR } \\
\left(\mathrm{kw} / \mathrm{m}^{2}\right)\end{array}$ & $\begin{array}{c}\text { THR } \\
\left(\mathrm{MJ} / \mathrm{M}^{2}\right)\end{array}$ & $\begin{array}{c}\text { AS-MLR } \\
(\mathrm{g} / \mathrm{ms})\end{array}$ & $\begin{array}{c}\text { ASEA } \\
\left(\mathrm{m}^{2} / \mathrm{kg}\right)\end{array}$ & $\begin{array}{c}\text { AEHC } \\
(\mathrm{MJ} / \mathrm{kg})\end{array}$ \\
\hline \multirow{2}{*}{ Core } & Core & 507.64 & 303.48 & 259.54 & 14.57 & 420.58 & 25.72 \\
\cline { 2 - 8 } & 0 & 982.74 & 384.5 & 397.95 & 15.54 & 455.57 & 30.12 \\
\hline \multirow{3}{*}{$\begin{array}{c}\text { Core-half } \\
\text { Whapped }\end{array}$} & 5 & 807.08 & 324.15 & 302.41 & 14.97 & 427.79 & 28.99 \\
\cline { 2 - 8 } & 15 & 789.87 & 300.58 & 298.93 & 14.19 & 421.03 & 25.93 \\
\cline { 2 - 8 } & 25 & 571.89 & 247.96 & 279.48 & 13.25 & 408.33 & 22.89 \\
\cline { 2 - 8 } & 35 & 476.34 & 222.09 & 260.96 & 13.01 & 398.97 & 21.68 \\
\cline { 2 - 8 } & 50 & 323.31 & 198.58 & 253.13 & 11.51 & 393.9 & 20.95 \\
\hline
\end{tabular}

$\mathrm{PHRR}=$ peak heat release rate; AHRR = average heat release rate; $\mathrm{THR}=$ total heat release; $A M L R=$ average mass loss rate; $A S E A=$ average specific extinction area; $A E H C=$ average effective heat of combustion

Parameter PHRR indicates the scale and extension of fire disasters. Composites containing more than $25 \mathrm{wt} \%$ talc in the shell had obviously lower PHRR values. The PHRR value of the core approached $507.5 \mathrm{KW} / \mathrm{m}^{2}$. Upon the introduction of the pure HDPE layer, PHRR of the general composite grew to $982.7 \mathrm{KW} / \mathrm{m}^{2}$, suggesting the detrimental impacts of HDPE on the flammability of WPC. The addition of talc lowered the value of PHRR of the composite. In condition that GF loaded shell content was maintained at $50 \mathrm{wt} \%$, composite PHRR was $67 \%$, inferior to the unmodified HDPE shell. Additionally, THR and AMLR decreased with the increase of GF. In consequence, the introduction of talc to the shell layer alleviated the combustion of WPCs in core-shell structure (Fig. 4).

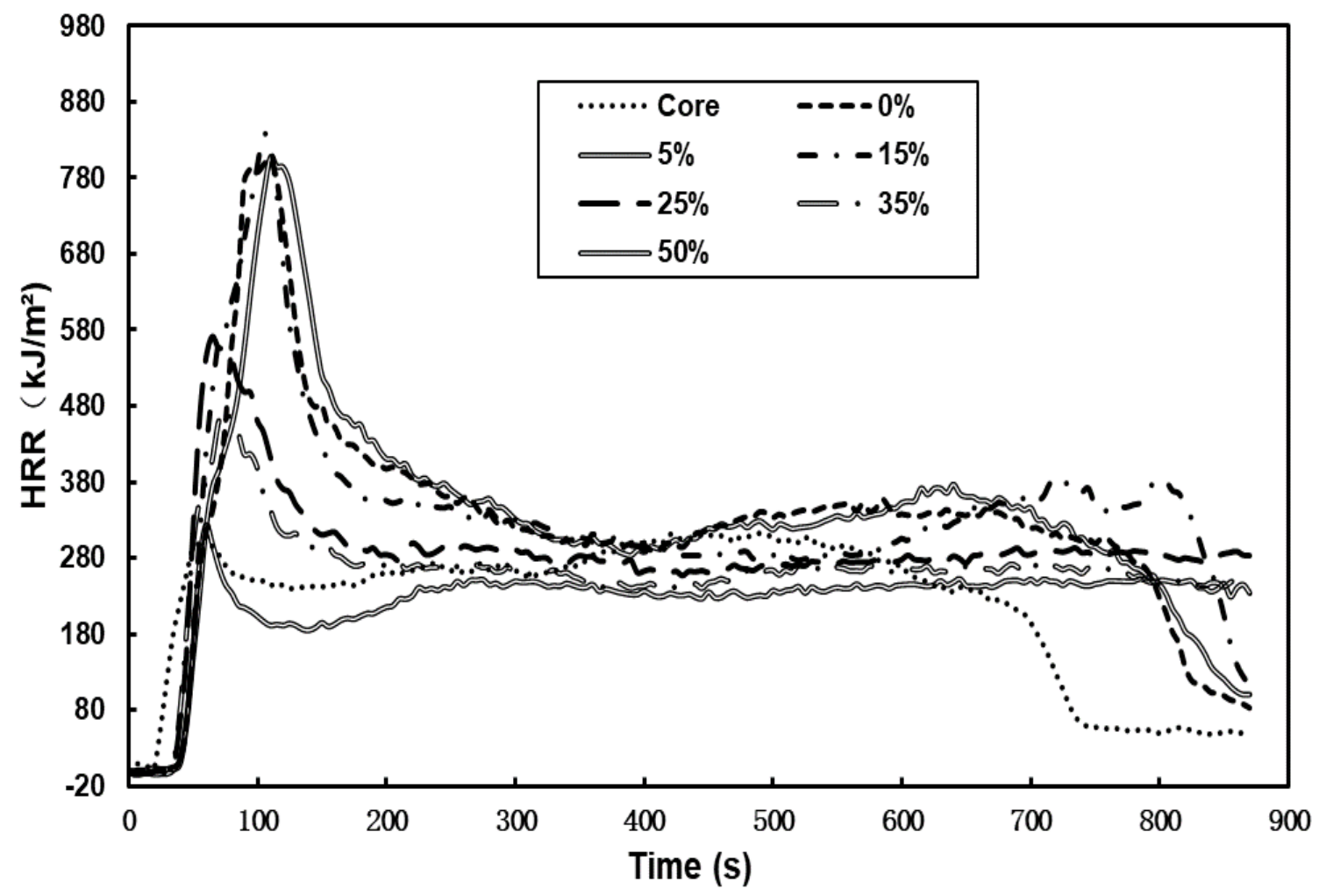

Fig. 4. Comparisons of HRR under different GF percentage contents 

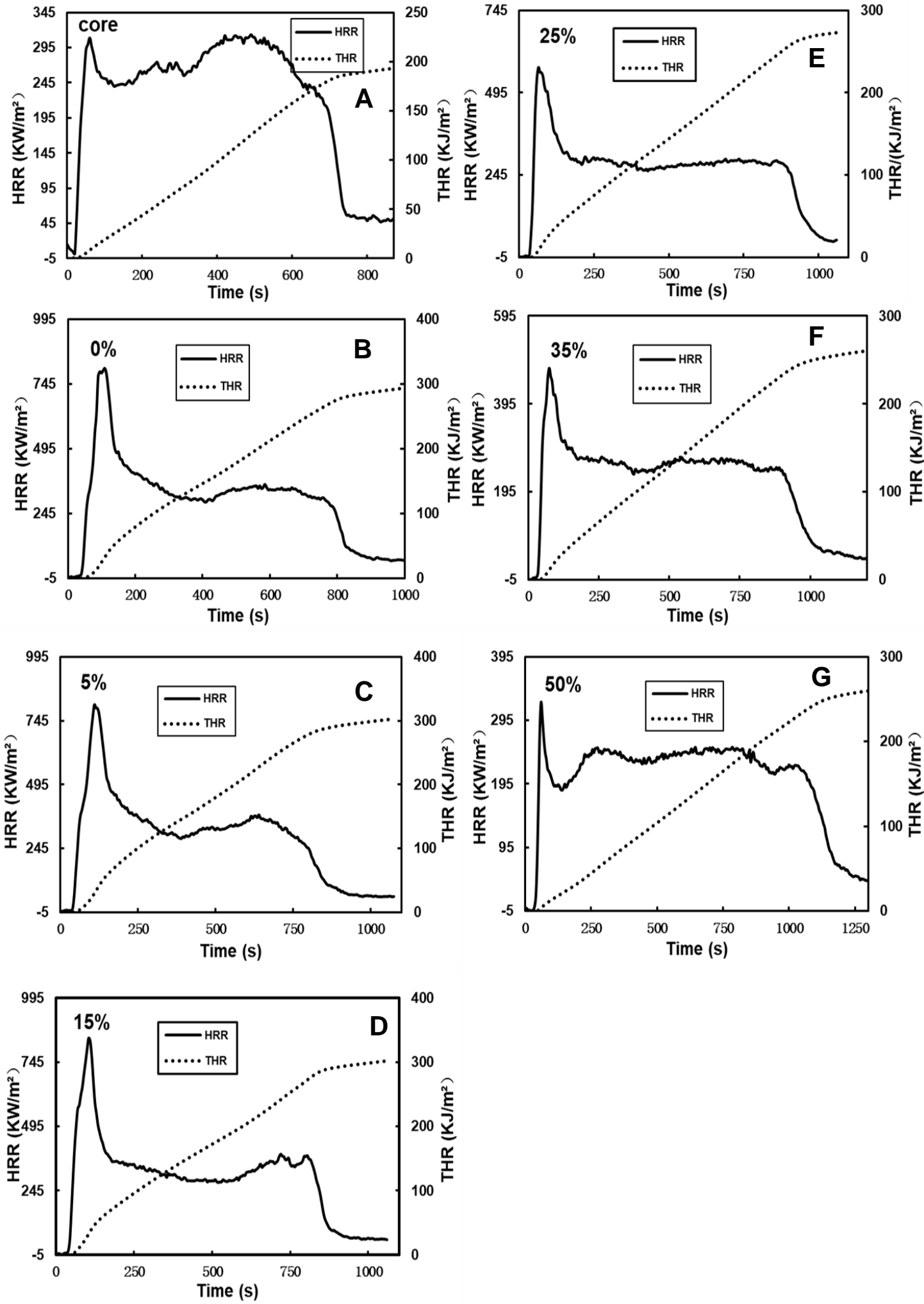

Fig. 5. HRR and THR curves of the same GF content in shell layer: A. Core, B. Pure HDPE shell, C. $5 \mathrm{wt} \%$ GF in shell, D. $15 \mathrm{wt} \%$ GF in shell, E. $25 \mathrm{wt} \%$ GF in shell, F. $35 \mathrm{wt} \%$ GF in shell, and G. $50 \mathrm{wt} \%$ GF in shell 
The heat release rate refers to the rate of heat release per unit area of material $\left(\mathrm{KW} / \mathrm{m}^{2}\right)$. The peak heat release rate represents the maximum value of HRR. The HRR a critical parameter indicative of fire behavior, which is defined as the fire intensity. For a high HRR or PHRR, the heat feedback onto the polymer material surface accelerated the pyrolysis rate, thus producing more volatile combustibles and accelerating the flame propagation. Consequently, polymer materials exhibited a higher risk in fire. In contrast, a lower HRR indicated better flame retardation of the material. The PHRR and AHRR were greatly reduced with the increased amount of GF. It was revealed that with the increased amount of GF, the pyrolysis rate and pyrolysis behavior of materials can be reduced under a certain fire intensity by a GF-reinforced shell layer (Djordjevic 1992; Yao et al. 2008; Huang et al. 2012). According to Table 2 and the HRR curve, the heat degradation rate to produce flammable volatile products greatly decreased with the increased GF content. Meanwhile, the time and distribution of flammable volatile product release tended to be stable, with an obvious flame retardation effect. The THR refers to the total heat release per unit area of material from the beginning of the combustion test to the end of the test $\left(\mathrm{MJ} / \mathrm{m}^{2}\right)$. On the whole, a greater THR indicated higher heat release during the combustion of the polymer material. In other words, the polymer material was associated with a high risk in fire. The combination of HRR with THR can accurately evaluate the material flammability and flame retardation (Singh et al. 2010; Huang et al. 2013).

As shown in Table 2, THR gradually decreased with the increased content of GF. The THR value of the core layer material was reached when the GF content increased to $50 \mathrm{wt} \%$. The HRR and THR curves of the same material are displayed in Fig. 5. During the flaming combustion stage from when the test specimen was ignited to the occurrence of the second peak, THR rapidly increased, and the fastest variation was detected at the peak of heat release. After the heat release peak, the THR slowly increased, suggesting that the heat released in combustion was mainly provided by flaming combustion. Consequently, suppressing flaming combustion was the key to flame retardation. According to the THR curve, these curves basically overlap at the GF contents of $0 \%, 5 \%$, and $15 \%$. When the GF content was higher than $15 \%$, THR significantly decreased, indicating that high GF contents markedly suppress heat release (Fig. 6).

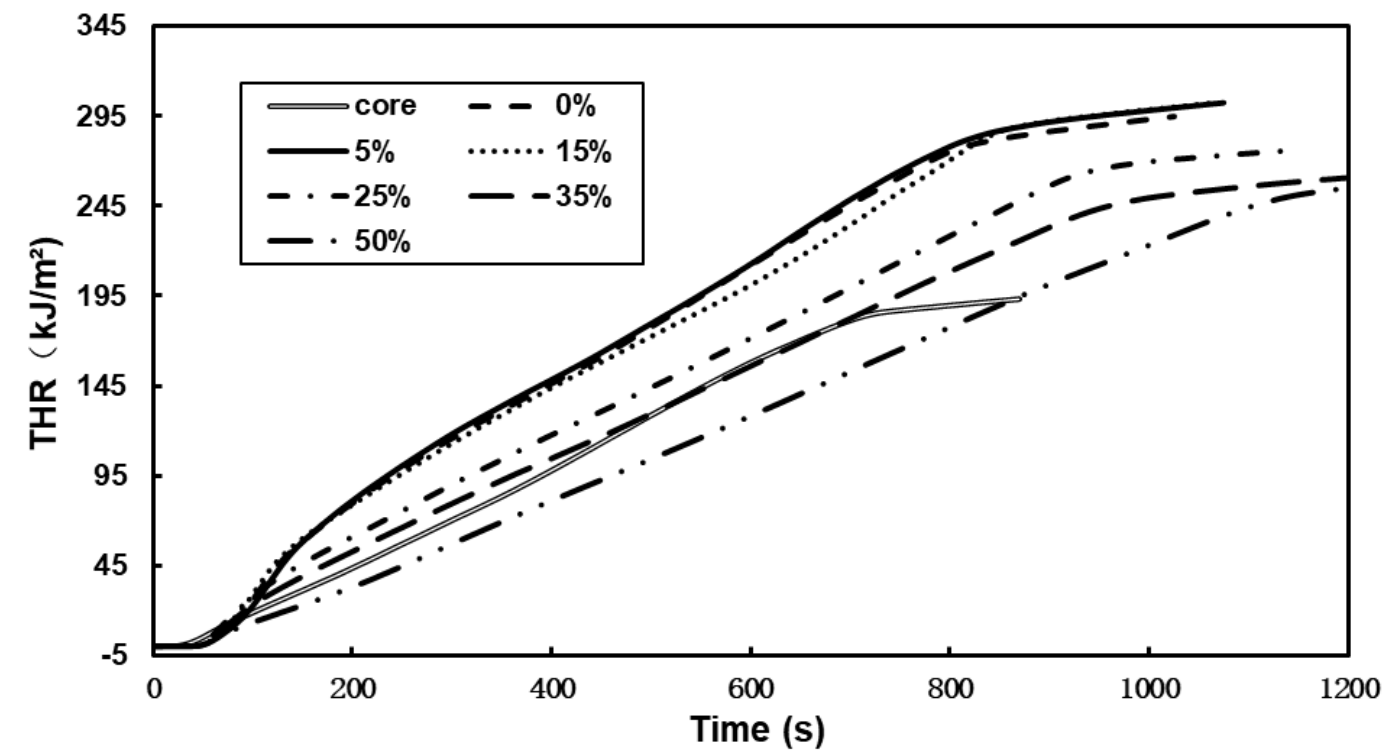

Fig. 6. Variation of THR with the GF content in shell layer 
The addition of GF led to the significant rise of THR. The THR value in WPC core was relatively lower $\left(259.54 \mathrm{MJ} / \mathrm{m}^{2}\right)$ than that in WPC core containing unmodified HDPE (397.95 $\mathrm{MJ} / \mathrm{m}^{2}$ ). The THR values for the composites at with 5 and $15 \mathrm{wt} \%$ of GF approximated the THR values of the core material in the first $50 \mathrm{~s}$. Therefore, with the addition of filler content, gross heat release was maintained at a stable level Whereas, in condition that the GF loading levels approached 5\%, the THR of the composite experienced a downward trend. Due to the rise of GF level, THR value of co-extruded WPCs was reduced from $302.41 \mathrm{MJ} / \mathrm{m}^{2}$ ( $5 \mathrm{wt} \%$ of GF) to $253.13 \mathrm{KW} / \mathrm{m}^{2}$ (50 wt $\%$ of GF).

The EHC refers to the ratio of the measured heat release amount to the mass loss amount at a certain time point $t(\mathrm{MJ} / \mathrm{kg})$, which reflects the combustion degree of flammable volatile gas in the gas phase flame. The EHC is also a measure of the flame retardation of materials when they burn. It is similar to the heat release rate curve. The lower curve data indicated better flame retardation properties. As shown in Table 2, AEHC gradually and modestly decreased with the increased content of GF.

The ASEA is a parameter to indicate the smoke generation capacity during material combustion. Regardless of materials, the graph outline of the combustion test data curve as a function of time was similar to that of polymer materials with the same base material. However, SEA data curves share similar shapes, in which the fluctuation of the tested data size is large and the graph curve tends to show the great spike fluctuation. In addition, the curve outline trend is irregular, and different materials display different curve morphologies. Meanwhile, for the polymer materials with the same base material, different fillings and compositions also lead to various outline trends of curves. In Table 2, ASEA substantially declines with the increased content of GF, indicating that the increased shell layer GF suppresses the smoke generation capacity during combustion. When the GF content was increased to $15 \%$ and $20 \%$, the ASEA was able to reach the value of the core layer material.

The MLR refers to the mass loss variation rate of polymer materials during combustion, $\mathrm{g} / \mathrm{s}$, and it reflects the pyrolysis rate and pyrolysis behavior of polymer materials under a certain fire intensity. In Table 2, AMLR gradually decreased with the increased amount of GF, suggesting that the pyrolysis rate and pyrolysis behavior of materials can be reduced under a certain fire intensity by a GF-reinforced shell layer. When the amount of GF was $0 \%$ to 5\%, AMLR basically reduced, indicating that a small portion of GF had the ability to significantly suppress pyrolysis.

Based on the SEM experiment, the HDPE matrix can combine with GF in the HDPE/GF composite. This was because GF particles were treated with silicon solution before granulation, which performs as the coupling agent. Therefore, the HDPE matrix was well combined with GF filling in the HDPE/GF composite due to the coupling agent. Moreover, the core layer and shell layer exhibited a favorable interfacial bonding, thus optimizing the modification effect of the shell layer material and enhancing the flame retardation effect. Moreover, compared with the core-shell WPC, the co-extrusion WPC with core-half wrapped obtained better thermal expansion property, leading to superior thermal stability of the composite. The GF can enhance the shell layer composite. Based on the analysis from cone calorimeter, the composite flame retardation gained improvements from the increased amount of GF.

The flame retardation mechanism of the co-extrusion WPC can be explained as follows. The shell layer and carbon in WPC will form a high-temperature resistant barrier to prevent heat and mass transmission when it is subjected to strong heat. During polymer combustion or gasification, bubbles result from the degradation of a large amount of 
products, and the melt flows from the polymer inside to surface, accelerating movement of the GF to the WPC surface. The decreased HRR was mainly attributed to the delay of the thermo-oxidative decomposition. Based on delayed thermo-oxidative decomposition and reduced HRR, the detachment of the shell layer had little effect on shielding volatiles. The dispersion, disperse state, and interfacial property of reinforcement fillers in the base material were the determinants that affect WPC flame retardation.

\section{CONCLUSIONS}

1. The core-half wrapped shell structure design can enhance the impact strength and flexural of composites by way of the coated shell layer. In consideration of the poor performance of composites in easy thermal expansion and low degree of stiffness in the shell layer, the composites demonstrated inferior thermal stability properties and flexural modulus.

2. Upon the incorporation of $25 \mathrm{wt} \%$ GF to the shell layer, improvements in thermal and mechanical properties could be achieved.

3. The impact strength of WPC cores was improved when an outer shell layer was applied to the core.

4. As GF content in the top shell was increased, the PHRR of HDPE-GF material was impaired due to the incomplete combustion of HDPE-GF material induced by loading GF.

5. The results in this study indicated that when GFs were applied to reinforce the shell layer, the amount of GF should not be less than $25 \%$ to $35 \%$. Otherwise, the expected flame retardation effect cannot be achieved. This was because at a low GF content, the wick effect of GF resulted in insignificant flame retardation effect at a low GF content.

\section{ACKNOWLEDGEMENTS}

The program was sponsored by major projects of the Natural Science Foundation of Jiangsu (18KJA220002); the China Postdoctoral Science Foundation: Special Program (2017T100313); the China Postdoctoral Science Foundation: General Program (2016M601821); and the Postdoctoral Science Foundation of Jiangsu Province: A Program (1601027A).

\section{REFERENCES CITED}

Ansari, F., and Navalurkar, R. K. (1993). "Kinematics of crack formation in cementations composites by fiber optics," Journal of Engineering Mechanics 119(5), 1048-1061. DOI: 10.1061/(ASCE)0733-9399(1993)119:5(1048)

ASTM D6272 (2002). "Standard test method for flexural properties of unreinforced and reinforced plastics and electrical insulating materials by four-point bending," ASTM International, West Conshohocken, PA, USA. 
Bengtsson, M., and Oksman, K. (2006). "Silane crosslinked wood plastic composites: Processing and properties," Composites Science and Technology 66(13), 2177-2186. DOI: $10.1016 /$ j.compscitech.2005.12.009

Djordjevic, D. (1992). Coextrusion, iSmithers Rapra Publishing, Shropshire, United Kingdom.

Huang, R., Xiong, W., Xu, X., and Wu, Q. (2012a). "Thermal expansion behavior of coextruded wood plastic composites with glass-fiber reinforced shells," BioResources 7(4), 5514-5526. DOI: 10.15376/biores.7.4.5514-5526

Huang, R., Zhang, Y., Xu, X., Zhou, D., and Wu, Q. (2012b). "Effect of hybrid mineral and bamboo fillers on thermal expansion behavior of bamboo fiber and recycled polypropylene-polyethylene composites," BioResources 7(4), 4563-4574. DOI: 10.15376/biores.7.4.4563-4574

Huang, R., Kim, B. J., and Lee, S. Y., Zhang, Y., and Wu, Q. L. (2013a). “Co-extruded wood plastic composites with talc filled shells: Morphology, mechanical and thermal expansion performance," BioResources 8(2), 2283-2299. DOI:

10.15376/biores.8.2.2283-2299

Huang, R. Z., Zhou, C. J., Zhang, Y., and Wu, Q. L. (2013b). "Co-extrusion technology for functioned nature fiber reinforced polymer composites," Advanced Materials Research 773, 497-501. DOI: 10.4028/www.scientific.net/AMR.773.497

ISO 5660-1 (20020). "Reaction-to-fire tests," International Organization for Standardization, Geneva, Switzerland.

Jin, S., and Matuana, L. M. (2010). "Wood/plastic composites co-extruded with multiwalled carbon nanotube-filled rigid poly(vinyl chloride) cap layer," Polymer International 59 (5), 648-57. DOI: 10.1002/pi.2745

Klyosov, A. A. (2007). Wood-plastic Composites, John Wiley \& Sons Inc., Hoboken, NJ, USA.

Kim, B. J., Yao, F., Wang, Q. W., and Wu, Q. L. (2013). "Mechanical and physical properties of core-shell structured wood plastic composites: Effect of shells with hybrid mineral and wood fillers," Composites Part B: Engineering 45(1), 1040-1048. DOI: 10.1016/j.compositesb.2012.07.031

Liu, H., Yao, F., Xu, Y., and Wu, Q. (2010). "A novel wood flour-filled composite based on microfibrillar high density polyethylene (HDPE)/nylon-6 blends," Bioresource Technology 101(9), 3295-3297. DOI: 10.1016/j.biortech.2009.12.073

Nielson, L. E., and Landel, R. F. (1993). Mechanical Properties of Polymers and Composites, 2nd edition, Marcel Dekker, New York, NY, USA.

Son, J., Gardner, D. J., O'Neill, S., and Metaxas, C. (2003). "Understanding the viscoelastic properties of extruded polypropylene wood plastic composites," Journal of Applied Polymer Science 89(6), 1638-1644. DOI: 10.1002/app.12372

Singh, S., Mohanty, A. K., and Misra, M. (2010). "Hybrid bio-composite from talc, wood fiber and bioplastic: Fabrication and characterization," Composites Part A: Applied Science and Manufacturing 41(2), 304-312. DOI: 10.1016/j.compositesa.2009.10.022

William, L. J. (1998). "Research needs in wood physics: A broad overview," Wood and Fiber Science 20(2), 277-294.

Yao, F., and Wu, Q. (2010). "Coextruded polyethylene and wood-flour composite: Effect of shell thickness, wood loading, and core quality," Journal of Applied Polymer Science 118(6), 3594-601. DOI: 10.1002/app.32742 
Yao, F., Wu, Q., Lei, Y., and Xu, Y. (2008). "Rice straw fiber reinforced high density polyethylene composite: Effect of fiber type and loading," Industrial Crops and Products 28(1), 63-72. DOI: 10.1016/j.indcrop.2008.01.007

Article submitted: April 23, 2020; Peer review completed: July 18, 2020; Accepted: September 21, 2020; Published: October 16, 2020.

DOI: $10.15376 /$ biores.15.4.9088-9102 